\title{
Infrared Spectrum of Hydrobromic Aid
}

\author{
Earle K. Plyler
}

\author{
(April 21, 1960)
}

\begin{abstract}
A precise measurement of the infrared fundamental bands of $\mathrm{HBr}^{79}$ and $\mathrm{HBr}^{81}$ has been made. The two band centers have been found to be $2,558.94$ and $2,558.56 \mathrm{~cm}^{-1}$, respectively. Rotational and vibrational constants have been calculated from the observed data. The constants are in good agreement with previous reported values. The centers of the two harmonic bands were used to calculate $\omega_{e} x_{e}$ and $\omega_{e} y_{e}$ and they were found to be 45.58 and $0.072 \mathrm{~cm}^{-1}$, respectively, for $\mathrm{HBr}^{79}$ and 45.56 and $0.072 \mathrm{~cm}^{-1}$ for $\mathrm{HBr}^{81}$.
\end{abstract}

\section{Introduction}

Hydrobromic acid was one of the first molecules whose spectrum was determined with a spectrometer of good resolution. ${ }^{1}$ The spectrum showed a series of lines which made up the $P$ - and $R$-branches of the band. With improved instruments it was possible to partially resolve some of the lines of the fundamental band into two components. ${ }^{2}$ These components arise from the two isotopes of bromine and the separation is about $0.4 \mathrm{~cm}^{-1}$. Naudé and Verleger ${ }^{3}$ measured the $4-0$ band of $\mathrm{HBr}$ in the photographic region and separated the isotopic bands. They calculated the rotational constants and their values will be compared with the results reported in this paper. More recently Thompson, Williams, and Callomon ${ }^{4}$ have measured the fundamental band with high resolution and have been able to separate the individual lines into two components. While the observed and calculated positions of the lines reported by them showed good agreement, it was thought that the absolute values of the line positions might be in error. A preliminary scan of the spectrum revealed that all the wavenumbers of the lines of $\mathrm{HBr}^{79}$ and $\mathrm{HBr}^{81}$ as measured by Thompson, Williams, and Callomon were too small by about $0.15 \mathrm{~cm}^{-1}$ and it was felt that a more precise measurement of the spectrum was needed so that this band could be used as a reference standard for calibration in the infrared region. Also, it was expected that a more accurate set of molecular constants could be obtained.

\section{Experimental Results}

The spectrum of $\mathrm{HBr}$ was observed on a high resolution spectrometer containing a grating with 10,000 lines/in. The ruled surface was $8 \frac{1}{4} \mathrm{in}$. and was used double pass. A cool lead sulfide cell served as the detector and the resolution of the instrument was about $0.04 \mathrm{~cm}^{-1}$. The components of a line arising from $\mathrm{HBr}^{79}$ and $\mathrm{HBr}^{81}$ were completely

\footnotetext{
1 H. M. Randall and E. S. Imes, Phys. Rev. 15, 152 (1920).

2 E K Plyler and F F Barker, Phys. Rev 44, 984 (1933)

2 E. K. Plyler and E. F. Barker, Phys. Rev. 44, 984 (1933)
3 S. H. Naudé and H. Verleger, Proc. Phys. Soc. 63 A, $470(1950)$.

${ }^{4}$ H. W. Thompson, R. L. Williams, and H. J. Callomon, Spectrochimica Act 5, 313 (1952).
}

separated. Further details of the instrument are given in a previous paper. ${ }^{5}$

The spectrum was measured by using the fringe system of a Fabry-Perot interferometer as a comparison spectrum. Reference standards were also superimposed on the recorded spectrum. Higher orders of the atomic lines of krypton were found to be well suited for the comparison spectrum.

A further method of insuring the absolute positions of the lines was employed. This method consisted of overlapping a section of the spectrum of $\mathrm{HBr}$ with that of the spectrum of $\mathrm{HCl}$ by putting both gases in the absorption cell, and then using the accurately known $\mathrm{HCl}$ lines as standards for the measurement of the $\mathrm{HBr}$ spectrum.

Figure 1 shows a section of the $\mathrm{HBr}$ spectrum from $R 5$ through $R 10$ overlapping the $\mathrm{HCl}$ spectrum from $P 8$ to P10. The wavenumbers for the $\mathrm{HBr}$ lines from $R 5$ to $R 10$ as found by the two methods of measurement agreed to $\pm 0.01 \mathrm{~cm}^{-1}$ and this result indicated that the absolute position of the band was well determined.

In order to have sufficient bands for determining the anharmonic terms $\omega_{e} x_{e}$ and $\omega_{e} y_{e}$ several lines of the first harmonic band were measured.

The calculated and observed positions of the rotational lines of the fundamental bands of $\mathrm{HBr}^{79}$ and $\mathrm{HBr}^{81}$ are listed in table 1 . The values of the molecular constants were calculated and are listed in table 2. The following equation was used in determining the rotational constants:

$$
\begin{aligned}
\nu= & \nu_{0}+\left(B_{1}+B_{0}\right) m+\left(B_{1}-B_{0}-D_{1}+D_{0}\right) m^{2}-\left(2 D_{1}+\right. \\
& \left.2 D_{0}-H_{1}-H_{0}\right) m^{3}-\left[\left(D_{1}-D_{0}\right)-3\left(H_{1}-H_{0}\right)\right] m^{4}+ \\
& 3\left(H_{1}+H_{0}\right) m^{5}
\end{aligned}
$$

where $m=J+1$ for the $R$-branch and $-J$ for the $P$-branch. The data of table 1 were reduced by means of an electronic computer.

The terms $\omega_{e}, \omega_{e} x_{e}$, and $\omega_{e} y_{e}$ are found by using the following equations:

$$
\left.\begin{array}{c}
\nu_{1-0}=\omega_{e}-2 \omega_{e} x_{e}+3 \frac{1}{4} \omega_{e} y_{e}, \\
2 \nu_{1-0}-\nu_{2-0}=2 \omega_{e} x_{e}-9 \omega_{e} y_{e}, \\
4 \nu_{1-0}-\nu_{4-0}=12 \omega_{e} x_{e}-78 \omega_{e} y_{e} .
\end{array}\right\}
$$

\footnotetext{
${ }^{5}$ E. K. Plyler and L. R. Blaine, J. Research NBS 62, 7 (1959) RP2922.
} 


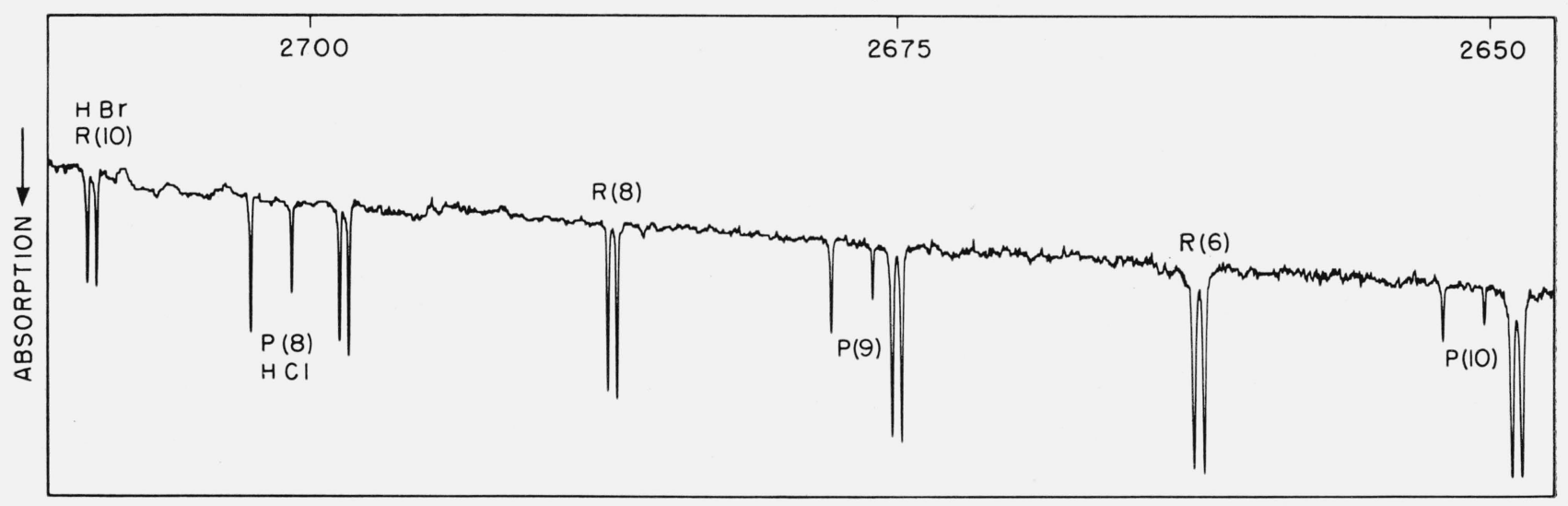

Figure 1. The absorption spectrum of $\mathrm{HBr}$ from $R 5$ to $R 10$ and $\mathrm{HCl}$ from P8 to P10.

The pressure of each gas was $2.5 \mathrm{~mm}$ with a cell length of $6 \mathrm{~m}$.

TABLE 1. The observed and calculated positions of the lines of the fundamental bands of $\mathrm{HBr}^{79}$ and $\mathrm{HBr}^{81}$

\begin{tabular}{|c|c|c|c|c|c|c|}
\hline \multicolumn{7}{|c|}{$\mathrm{HBr} 79$} \\
\hline $\mathrm{J}$ & $R_{\text {obs }}$ & $P_{\text {obs }}$ & $R_{\text {ealo }}$ & $P_{\text {ealo }}$ & $R_{\text {obs-calc }}$ & $P_{\text {obs-calc }}$ \\
\hline 0 & $2,575.181$ & & $2,575.176$ & & 0.005 & \\
\hline 1 & $2,590.945$ & $2,542.240$ & $2,590.939$ & $2,542.237$ & .006 & 0.003 \\
\hline 2 & $2,606.221$ & $2,525,075$ & $2,606.222$ & $2,525.079$ & -.001 & -.004 \\
\hline 3 & $2,621,012$ & $2,507,472$ & $2,621.016$ & $2,507.472$ & -.004 & .000 \\
\hline 4 & $2,635.314$ & $2,489.423$ & $2,635.314$ & $2,489.427$ & .000 & -.004 \\
\hline 5 & $2,649.110$ & $2,470.949$ & $2,649.111$ & $2,470.953$ & -.001 & -.004 \\
\hline 6 & $2,662.392$ & $2,452.063$ & $2,662.392$ & $2,452.059$ & .000 & .004 \\
\hline 7 & $2,675.155$ & $2,432.757$ & $2,675.156$ & $2,432.756$ & -.001 & .001 \\
\hline 8 & $2,687.393$ & $2,413,060$ & $2,687.395$ & $2,413.055$ & -.002 & .005 \\
\hline 9 & $2,699.102$ & $2,392.964$ & $2,699.100$ & $2,392.968$ & .002 & -.004 \\
\hline 10 & $2,710.266$ & & $2,710.263$ & & .003 & \\
\hline 11 & $2,720.876$ & & $2,720.871$ & & .005 & - \\
\hline 12 & $2,730.928$ & & $2,730.931$ & & -.003 & \\
\hline 13 & $2,740.421$ & - & $2,740.420$ & & .001 & -.... \\
\hline 14 & $2,749.333$ & $-1-2-2-2$ & $2,749.333$ & & .000 & $-n$ \\
\hline
\end{tabular}

\begin{tabular}{|c|c|c|c|c|c|c|}
\hline \multicolumn{7}{|c|}{$\mathrm{HBr}^{81}$} \\
\hline 0 & $2,574.789$ & & $2,574.790$ & & -0.001 & 1 \\
\hline 1 & $2,590.555$ & $2,541.865$ & $2,590.549$ & $2,541.862$ & .006 & 0.003 \\
\hline 2 & $2,605.831$ & $2,524.710$ & $2,605.827$ & $2,524.709$ & .004 & .001 \\
\hline 3 & $2,620.612$ & $2,507.102$ & $2,620.616$ & $2,507.108$ & -.004 & -.006 \\
\hline 4 & $2,634.907$ & $2,489.062$ & $2,634.909$ & $2,489.068$ & -.002 & -.006 \\
\hline 5 & $2,6448,701$ & $2,470.598$ & $2,648,699$ & 2.470 .598 & .002 & .000 \\
\hline 6 & $2,661.976$ & $2,451.718$ & $2,661.977$ & $2,451.709$ & -.001 & .009 \\
\hline 7 & $2,674.732$ & $2,432.408$ & $2,674.737$ & $2,432.411$ & -.005 & -.003 \\
\hline 8 & $2,686.969$ & $2,412,717$ & $2,686.972$ & $2,412.714$ & -.003 & .003 \\
\hline 9 & $2,698.674$ & 2. 392.628 & $2,698.678$ & $2,392.630$ & -.004 & -.002 \\
\hline 10 & $2,709.842$ & & $2,709.844$ & & -.002 & \\
\hline 11 & $2,720.448$ & & $2,720.444$ & & .004 & \\
\hline 12 & $2,730.494$ & & $2,730.498$ & & -.004 & \\
\hline 13 & $2,739.988$ & & 2. 739.989 & & -.001 & \\
\hline 14 & $2,748.907$ & & $2,748.906$ & & .001 & \\
\hline
\end{tabular}

The observed wavenumbers of $\nu, 2 \nu$, and $4 \nu$ and the calculated values of $\omega_{e}, \omega_{e} x_{e}$, and $\omega_{e} y_{e}$ are given in table 3 . The band centers for $\nu$ and $2 \nu$ have been determined in this work, but the value of $4 \nu$ has been taken from the work of Naudé and Verleger (see footnote 3, page 377).

The constants reported in table 2 are in good agreement with the results of Naudé and Verleger and
TABLE 2. The calculated constants of $\mathrm{HBr}^{79}$ and $\mathrm{HBr}^{81}$ in $\mathrm{cm}^{-1}$

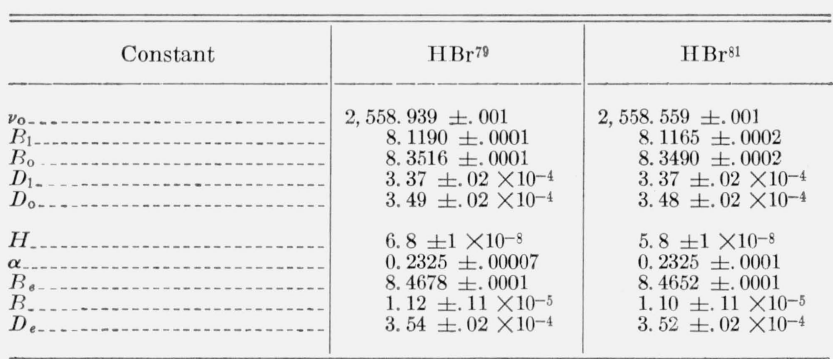

those of Thompson, Williams, and Callomon, but the reported values differ more than the estimated accuracy given in the different reports. The greatest difference between the results reported in this paper and those of Thompson, Williams, and Callomon is the position of the band centers. They report $\nu_{0}=$ 2,558.76 $\mathrm{cm}^{-1}$ for $\mathrm{HBr}^{79}$ and $\nu_{0}=2,558.40 \mathrm{~cm}^{-1}$ for

TABLE 3. The vibrational constants of $\mathrm{HBr}^{79}$ and $\mathrm{HBr}^{81}$ in $\mathrm{cm}^{-1}$

\begin{tabular}{|c|c|c|}
\hline Constant & $\mathrm{HBr}^{79}$ & $\mathrm{HBr}^{81}$ \\
\hline $\begin{array}{l}\nu_{2} \nu_{-} \\
4 \nu_{-} \\
\omega_{e}-\ldots \\
\omega_{e} x_{e} \\
\omega_{e} y_{e-\ldots}\end{array}$ & $\begin{array}{c}2,558.939 \\
5,027.378 \\
9,694.495 \\
2,649.855 \\
45.576 \\
0.0724\end{array}$ & $\begin{array}{r}2,558.559 \\
5,026.636 \\
9,693.151 \\
2,644.450 \\
45.564 \\
0.0726\end{array}$ \\
\hline
\end{tabular}

$\mathrm{HBr}^{81}$, while our measurements give the band centers at $2,558.94 \mathrm{~cm}^{-1}$ and $2,558.56$, respectively. Also, the $B_{0}$ values for the two molecules are greater by $0.0018 \mathrm{~cm}^{-1}$ in the measurements of Thompson, Williams, and Callomon than calculated from our measurements. It is believed that the molecular constants of $\mathrm{HBr}$ here presented are more precise than any previously reported. The probable error 
of the constants have been calculated and are included in table 2.

On the condition that the ratio of the molecular constants for $\mathrm{HBr}^{79}$ and $\mathrm{HBr}^{81}$ are only a function of the masses, the constants listed in table 2 for $\mathrm{HBr}^{81}$ have been calculated from the values of $\mathrm{HBr}^{79}$. The agreement between the molecular constants of $\mathrm{HBr}^{81}$ calculated from the measured lines listed in table 1 and the values calculated from $\mathrm{HBr}^{79}$ by the isotopic effect are all within the limit of the listed experimental error. This indicates that the relative values of the molecular constants for $\mathrm{HBr}^{79}$ and $\mathrm{HBr}^{81}$ are in excellent accord.

The error in the constants $D$ and $H$ is larger than in the $B$ values. Only when a band has many lines which include large $J$ values do these constants have a significant effect on a line position. That is, from eq (1) it is seen that the greatest contribution of $H$ and $D$ to the line position occurs in the terms $\mathrm{m}^{3}$, $m^{4}$, and $m^{5}$.
There are relationships between the molecular constants so that some of them can be calculated from the known values of others. For example, $D_{e}$ can be obtained from $B_{e}$ and $\omega_{e}$ by the following relation:

$$
D_{e}=4 B_{e}^{3} / \omega_{e}^{2}
$$

From the above relation $D_{e}=3.459 \times 10^{-4} \mathrm{~cm}^{-1}$ for $\mathrm{HBr}^{79}$ and $D_{e}=3.457 \times 10^{-4} \mathrm{~cm}^{-1}$ for $\mathrm{HBr}^{81}$. These calculated constants are about two percent smaller than those obtained from the experimental data.

The author is indebted to Jessie Kirkland and Mary C. Dannemiller for assistance in reducing the data. 